\title{
The future of hotel rating
}

\section{Wouter Hensens}

Dr Wouter Hensens is based at Stenden South Africa Campus, Stenden University, Port Alfred, South Africa.
(C) Wouter Hensens. Published in the Journal of Tourism Futures.

This article is published under the Creative Commons Attribution (CC BY 4.0) licence. Anyone may reproduce, distribute, translate and create derivative works of this article (for both commercial and non-commercial purposes), subject to full attribution to the original publication and authors. The full terms of this licence may be seen at: http://creativecommons.org/ licences/by/4.0/legalcode

\begin{abstract}
Purpose - The purpose of this paper is to provide an insight in the future of hotel rating. It reviews the impact of social media, technology that provides integration of data for the consumer and the hotels, and the way that rating bodies may respond to the changing environment on how hotels are selected and reviewed.

Design/methodology/approach - By reviewing current trends, practices and technological possibilities, the impact of online reviews on conventional hotel rating systems is projected into the future.

Findings - The paper predicts a full integration of conventional rating systems with online guest reviews from the different guest review platforms leading to greater transparency for the consumer and better positioning opportunities for innovative hotels. It is further predicted that those conventional rating systems that do not seek integration and alignment will see a continued drop in hotel participation and will cease to exist.
\end{abstract}

Originality/value - Little research has been done on the relation between online guest reviews and conventional hotel rating systems. The paper presents new insights into how current and future trends influence the way in which consumers select hotels and how this influences the way that hotels are rated.

Keywords Marketing, Social media, Guest reviews, Hotel classification, Hotel rating, Online reputation management

Paper type Viewpoint

\section{Introduction}

With the continued growth of social media platforms for guest feedback, the playing field for hotel ratings is changing rapidly. Though hoteliers and the travel trade were at first sceptical about review platforms such as TripAdvisor (www.tripadvisor.com), this attitude is changing rapidly. The changing focus of consumers from conventional hotel rating systems that provide stars to classify hotels to online guest reviews and ratings is changing the field from one whereby the expert inspector or government dictates hotel standards to one whereby the consumer almost directly dictates what constitutes hotel quality.

This paper first explores the development of social media platforms facilitating guest reviews and ratings, looking specifically on how this impacts conventional rating systems. Second, the advancements in technology are being investigated. Third, the existing and future use of such technology by the hotel consumer, the hotel industry and conventional rating bodies is outlined, resulting in a prediction of what hotel rating will look like in 2024.

\section{The impact of social media on conventional hotel rating systems}

A multitude of organisations are involved in the rating of hotels. These organisations can be divided into two categories, namely, national and independent bodies. National organisations can be defined as bodies run by, or for a destination's government and independent organisations represent automobile associations, travel media, online travel agents and social media. Figure 1 outlines how these organisations supply information on the quality of hotels to the prospective traveller.

Figure 1 displays a wide variety of communication lines through which the information of hotel quality, typically through some form of rating system, is shared and supplied to prospective travellers. 


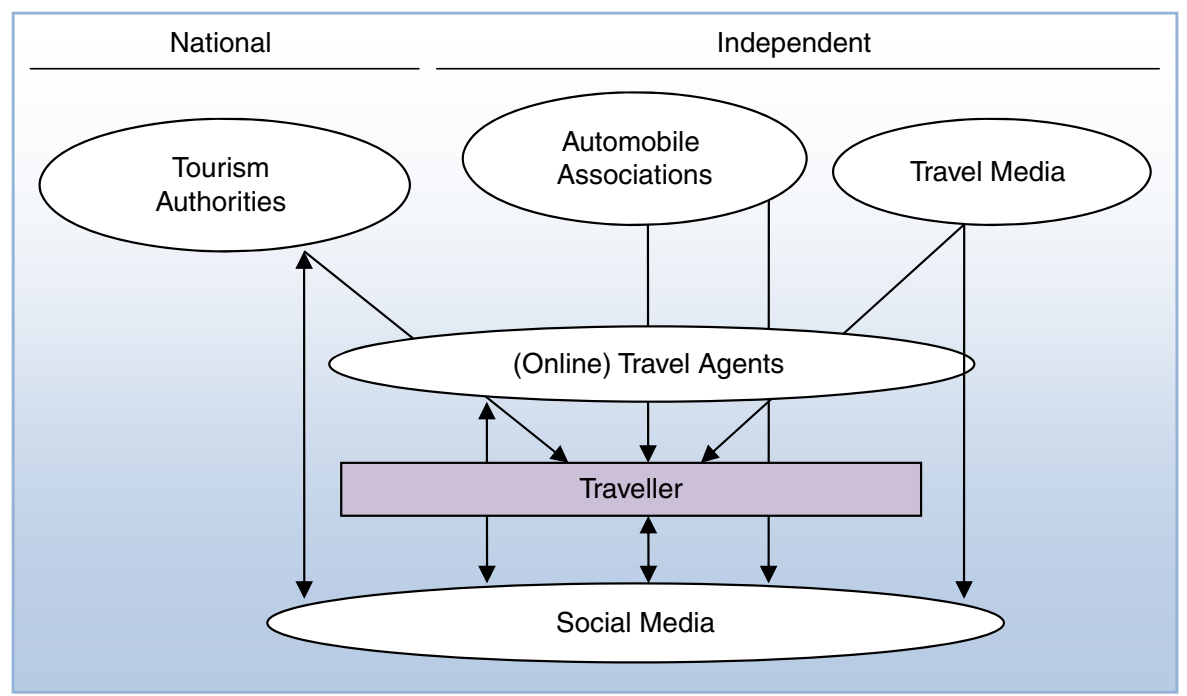

Source: Hensens et al. (2010)

The reason why governments get involved in hotel rating lies in the fact that tourism lodging has a major impact on the tourist experience and thus its quality must be managed. The rise of online feedback on social media, however, shifts the focus of the consumer and, as a consequence, the hoteliers to these platforms. Online guest feedback on social media platforms was initially subject of much discussion and controversy. TripAdvisor as the largest and fastest growing platform was at the centre of this. Although especially TripAdvisor's methods were subject to intense criticism (see for instance ABC News, 2008; Elliott, 2009; Frommer, 2009; O'Neill, 2009), its growth has led to an acceptance by the hotel industry and the travel trade alike.

Research by Hensens et al. (2010) suggests that the focus of guest reviews and ratings on TripAdvisor is different from the focus of most conventional rating criteria. Whereas most of the comments made in TripAdvisor reviews focus on service quality, most conventional rating systems tend to focus primarily on objective tangible criteria such as the availability and size of facilities and services, occasionally on subjective tangible criteria such as cleanliness and state of maintenance, and rarely on service quality (Hensens et al., 2010). It may therefore be argued that conventional rating systems and social media platforms such as TripAdvisor may complement each other. This is outlined in Figure 2.

However, one of the preconditions for this to happen is the sharing of accurate information, which initially did not happen (Pascarella, 2005; Hewitt, 2008). A number of recent initiatives outline the future possibilities. The Emirate of Abu Dhabi is the first destination to incorporate online ratings and feedback into its classification system (Thiessen, 2013; Edgcumbe, 2014) and a second project involving the author is underway for the Kingdom of Bahrain. The technology used to facilitate this integration is a clear catalyst in this process.

\section{Technology as a driver: mobile devices and online reputation management software}

The growth in the creation and use of online guest feedback for hotel rating continues as travellers start using mobile devices for travel planning and software provides integration across devices. TripAdvisor, for instance, reports a 150 per cent growth in the download of its travel apps for mobile devices with a total of 82 million downloads (TripAdvisor, 2014).

As more reviews are being posted over more platforms, online reputation companies have popped up that provide the service of integrating and analysing this online feedback data. Presently, there 


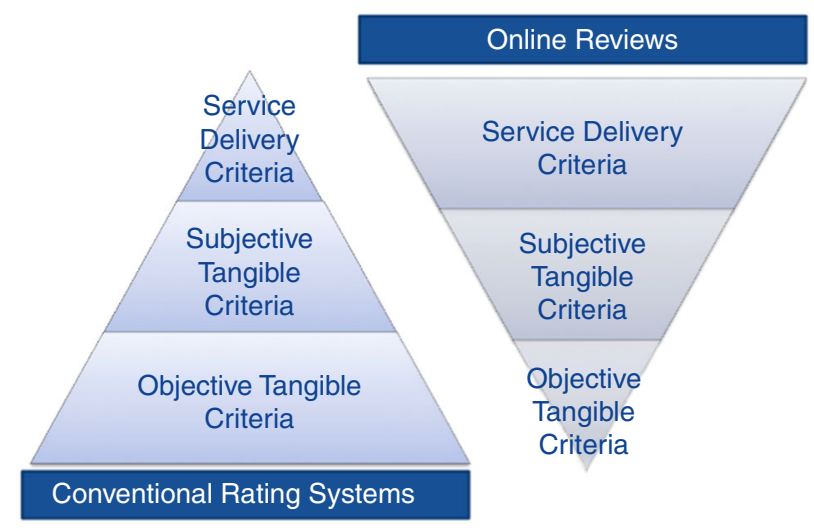

Source: Adapted from Hensens (2011)

are several companies operating in this market, three examples being: Olery.com (www.olery.com), ReviewPro (www.reviewpro.com) and Revinate (www.revinate.com). The services offered by these companies generally comprise of:

1. The pulling together of reviews and ratings in one dashboard from up to 100 different review platforms (Olery.com, 2014).

2. The integration and weighting of scores through an algorithm based on a number of variables (e.g. reliability of the review platform), providing a holistic score, typically on a scale from 1-100. Olery.com calls this the "Guest Experience Index" and ReviewPro refers to it as the "Global Review Index" (Olery.com, 2014; ReviewPro, 2014).

3. The comparison of hotel performance within a group, or a competitive set.

4. The live monitoring whereby push notifications can be set for ratings below a predefined threshold.

5. The provision for hoteliers to respond to reviews in one platform.

The information generated by such platforms is beneficial to hotels in that they have a direct feedback loop on what guests appreciate and where improvements can be made. This functionality can, however, also be used to integrate the data from online feedback platforms in the conventional hotel classification process which is the case in the new Abu Dhabi hotel classification system.

\section{Online reputation management software for a tourism destination: the case of Abu Dhabi}

Olery.com is the first of the reputation management company to provide an extended version of its product to the Abu Dhabi Tourism Authority (Edgcumbe, 2014) and the Bahrain Ministry of Culture (ExceedHospitality, 2014). The proposed procedure of monitoring for Abu Dhabi is proposed to be as follows:

1. Each hotel rating requires a minimum online rating score. Though certain destinations show little relation between conventional hotel ratings and average ratings on social media (Hensens, 2011), the United Arab Emirates show this relation clearly (Olery, 2012).

2. When a hotel scores below its minimum online rating score, integrated word recognition software is used to identify the key elements where the hotel falls short.

3. These elements are then validated through a mystery shopping assessment and, when confirmed, will lead to the hotelier receiving a warning and being given a period of time to rectify the issue. 
4. If the issue is not rectified within the given time frame the conventional rating is adjusted downwards to a rating that corresponds with the online rating score.

Step three in the four-step process is inserted to confirm the social media data. It is expected that as the acceptance of social media data by the hotel industry continues to grow, this step will be eliminated. Abu Dhabi has the advantage that by law, each hotel must be rated by its tourist authority and as such, all hotels must participate. This is not the case for many other destinations and this is a major limitation for such systems.

\section{Dropping participation in conventional rating systems}

In the study by Hensens (2011), it was found that almost half of 110 hotels from 11 destinations did not have a conventional rating despite the sample consisting of the top ten highest ranked hotels on TripAdvisor. In short, these were the top hotels in the respective destinations that chose not to be rated by their national rating body. Such poor participation presents a negative cycle that is expected to decrease participation further. This is outlined in Figure 3.

Figure 3 shows that the limited control of a conventional hotel rating system over hotels originates from two key elements, namely, legislative control and marketing support. If a system does not have legislative control, there must be an incentive for hoteliers to subject themselves to the rating system. The only other incentive is marketing exposure. Many rating systems offer listing and other marketing exposure when hotels participate in the system. However, as the marketing exposure is typically low compared to the exposure hotels can get through online travel agents, search engines or TripAdvisor.

\section{Hotel rating in 2024}

From the trends outlined above, a number of predictions can be made that will shape hotel rating over the next ten years. First, online guest feedback will continue to grow and be used more by more people. They key drivers are mobile devices and internet connectivity that allows travellers to write and read online reviews and ratings across devices, when and where they want. Conventional hotel rating systems will see a further drop in participation unless they have a legal base to enforce participation. To continue to justify their existence, conventional hotel rating systems will seek integration with social media, making the guests opinion an integral part of the rating process.

Figure 3 Expected decline of conventional rating participation

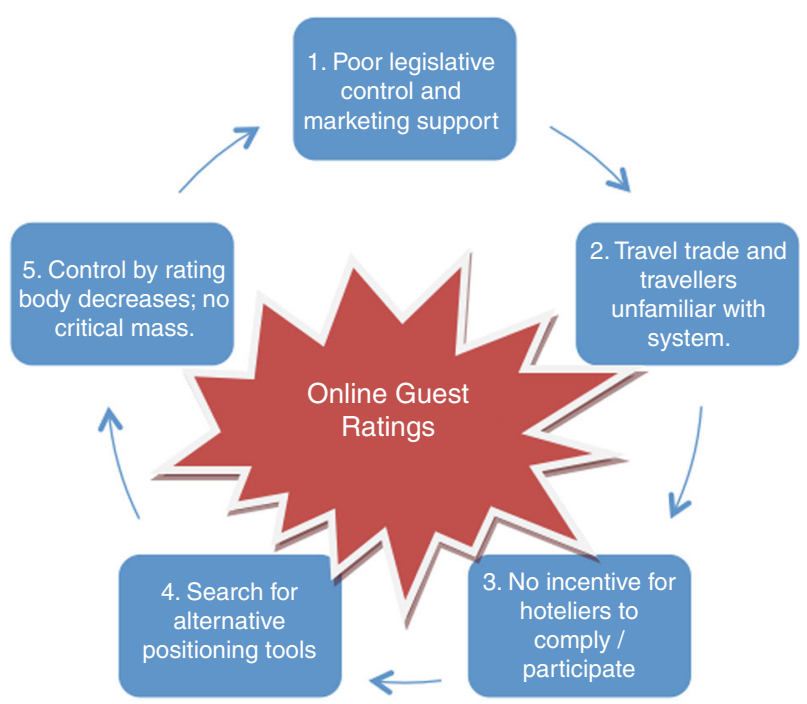

Source: Adapted from Hensens (2011) 
As conventional rating systems seek this alignment, the hotel product will be shaped more directly by what consumers appreciate and not what expert inspectors dictate. This democratisation of the rating process will lead to an innovation revolution whereby hotels seek to respond quicker to consumer trends as they have a direct feedback loop to their position in the market.

\section{References}

ABC News (2008), "Buyer beware: don't believe everything you read: a hotel might get rave reviews online, but who's writing them?", ABC News, 4 January, available at: http://abcnews.go.com/Travel/ BusinessTravel/story?id=4086830\&page=1 (accessed 1 December 2009).

Edgcumbe, D. (2014), "Abu Dhabi hotel ratings to go social in 2014, HotelierMiddleEast", available at: www.hoteliermiddleeast.com/19456-abu-dhabi-hotel-ratings-to-go-social-in-2014/-.UOBUhVwWXIY (accessed 5 April 2014).

Elliott, C. (2009), "Does TripAdvisor hotel manipulation scandal render the site completely useless?", 11 June, available at: www.elliott.org/blog/does-tripadvisor-hotel-manipulation-scandal-render-the-sitecompletely-useless/ (accessed 10 November 2009).

Frommer, A. (2009), "TripAdvisor is now warning you that numerous hotels are submitting phony recommendations for themselves", 10 June, available at: www.frommers.com/blog/?plckController=Blog\&plck Script=blogScript\&plckElementld=blogDest\&plckBlogPage=BlogViewPost\&plckPostld=Blog:3ec3ac40db8a-4d10-a884-acf9ccad0879Post:a9f7affe-fb7f-48b2-a9a6-34fb438ab5cf (accessed 10 November 2009).

Hensens, W. (2011), "Hotel rating through guest feedback", doctoral thesis, Nelson Mandela Metropolitan University, Port Elizabeth, available at: http://hdl.handle.net/10948/1631 (accessed 5 April 2014).

Hensens, W., Struwing, M. and Dayan, O. (2010), "Guest-review criteria on TripAdvisor compared to conventional hotel-rating systems to assess hotel quality", EuroCHRIE Annual Conference, Amsterdam, 25-28 October, available at: http://dspace.nmmu.ac.za:8080/jspui/bitstream/10948/1631/4/ArticleEuro Chrie 2010.pdf (accessed 5 April 2014).

Hewitt, E. (2008), "Star quality: what's in the rating?", Independent Traveller, 17 September, available at: http:// independenttraveler.com/resources/article.cfm?AID=629\&category=13\&page=1 (accessed 5 April 2014).

Olery.com (2012), "What do guests think? A report on the online reputation of UAE hotels", available at: http://l.olery.com/uae-report/?_ga=1.212557079.2033310328.1366259764 (accessed 5 April 2014).

Olery.com (2014), "Online reputation", available at: www.olery.com:reputation (accessed 5 April 2014).

O'Neill, S. (2009), "TripAdvisor tries to respond to fake hotel reviews", Newsweek, 11 June, available at: http:// current.newsweek.com/budgettravel/2009/06/tripadvisor_tries_to_respond_t.html (accessed 5 April 2014).

Pascarella, S. (2005), "Deciphering hotel star-rating confusion”, USA Today, 19 January, available at: www.usatoday.com/travel/deals/inside/2005-01-19-column_x.htm (accessed 5 April 2015).

ReviewPro (2014), "Global Review Index (GRI)", available at: www.reviewpro.com/products/features/globalreview-index (accessed 5 April 2014).

Thiessen, T. (2013), "Abu Dhabi folds reviews into hotel ratings", Hotel News Now, available at: www.hotelnewsnow.com/Article/12718/Abu-Dhabi-folds-reviews-into-hotel-ratings (accessed 5 April 2014).

TripAdvisor (2014), "Fact sheet", available at: www.tripadvisor.com/PressCenter-c4-Fact_Sheet.html (accessed 5 April 2014).

\section{Further reading}

Olery.com (2013), "Olery to provide technology for world's first social media powered hotel classification system", available at: www.olery.com/blog/olery-provide-technology-worlds-first-social-media-poweredhotel-classification-system/ (accessed 5 April 2014).

\section{Corresponding author}

DrWouter Hensens can be contacted at: wouter.hensens@stenden.ac.za 